Aim of the study: To present a case of a patient with cervical carcinoma in stage IIA who was diagnosed with pelvic bone sarcoma 28 years after radiotherapy. Case presentation: A 37-year-old woman with IIA cervix cancer was treated with external beam irradiation and brachytherapy. The patient had undergone conventionally fractionated external beam irradiation using the "box" technique, with the total dose of $50 \mathrm{~Gy}$ and brachytherapy with radium applicators (intrauterine tube and fornix applicator) with the dose of $60 \mathrm{~Gy}$ calculated at point A. After treatment she was followed up for 2 years. Twenty-six years later, inoperable pelvic bone sarcoma was diagnosed within the irradiated field. The clinical course was aggressive and rapid progression during chemotherapy was observed.

Conclusions: For patients receiving radiotherapy, long-term careful followup is mandatory due to second cancer risk. In the case of any suspicious symptoms, such patients need proper diagnosis to detect any disease as early as possible.

Key words: cervix cancer, radiotherapy, pelvic bones, radiation-induced sarcoma.

\section{Irradiation-induced bone sarcoma in a patient treated for cervix cancer 28 years earlier}

\author{
Małgorzata Klimek ${ }^{1}$, Wacław Wilk², Sława Szostek ${ }^{3}$, Elżbieta Łuczyńska4, \\ Tomasz Bieda', Zbigniew Kojs ${ }^{1}$, Janusz Ryś ${ }^{2}$
}

${ }^{1}$ Gynaecology Oncology Department, Maria Skłodowska-Curie Memorial Cancer Centre and Institute of Oncology, Kraków, Poland

2Pathology Department, Maria Skłodowska-Curie Memorial Cancer Centre and Institute of Oncology, Kraków, Poland

${ }^{3}$ Virusology Division, Chair of Microbiology, Jagiellonian University Medical Faculty, Kraków, Poland

4Radiology Department, Maria Skłodowska-Curie Memorial Cancer Centre and Institute of Oncology, Kraków, Poland

\section{Introduction}

An increasing number of women survive after cervical carcinoma treatment and live longer than 5-10 years without signs of recurrence. Some of these survivors may develop a second cancer caused by primary anticancer treatment. Aging is the most important factor of second cancer risk in cured cancer patients. Post-irradiation tumours can occur even 60 years after radiotherapy. Both chemotherapy and radiotherapy increase the risk of second cancer [1]. Epidemiological data concerning irradiation-induced sarcoma risk showed an average relative risk of 1.42 at $1 \mathrm{~Sv}$ (unit of dose equivalent, for gamma irradiation $1 \mathrm{~Sv}=1 \mathrm{~Gy}$ ) [2]. Incidence of radiation-induced tumours ranges from $0.5 \%$ to $1.6 \%$. We present a case of radiation-associated sarcoma of pelvic bone following radiotherapy for cervical carcinoma. The diagnostic and therapeutic dilemmas and mechanisms of development of irradiation-induced sarcoma are discussed.

\section{Case description}

A 37-year-old Polish woman was referred to the Institute of Oncology in Krakow in July of 1980 with diagnosis of squamous cell cervical carcinoma in FIGO stage IIA. Between 31 July and 2 September 1980, the patient underwent conventionally fractionated external beam irradiation with the total dose of 50 Gy and brachytherapy with radium applicators (intrauterine tube and fornix applicators) with the dose of 60 Gy calculated at point A. The patient was followed without signs of recurrence until March 1982. She was again referred to our hospital in May of 2008, 28 years after radiotherapy. For five months, the patient had been suffering from pain spreading from the back to the right sacroiliac joint. On gynaecological examination no signs of cervix cancer recurrence were found. X-ray of the pelvic bones showed an osteolytic focus of about $5 \mathrm{~cm} \times 8 \mathrm{~cm}$, in the right iliac ala at the level of the right sacroiliac joint. A computed tomography (CT) scan confirmed the presence of inoperable osteolytic destruction in the right iliac ala along the sacroiliac joint, with penetration into the articular space and inflammatory reaction in surrounding soft tissues. The imaging results were returned to the patient, so the present paper does not contain any photographic documentation of the examinations performed. Ultrasound controlled core-needle biopsy revealed malignant spindle cell neoplasm forming either long and storiform fascicles or haemangiopericytoma-like texture (Fig. 1). The tumour cells were characterized by numerous pleomorphic cells and significant mitotic activity [up to 2-3 mitotic figures in one high power field (HPF)] (Fig. 2). The tumour cells dyed positively with 
antibodies against vimentin (strong diffuse cytoplasmic reaction), CD68 and desmin (positive reaction in single cells) (Fig. 2. Insert). The immunohistochemical staining for broad spectrum of cytokeratins (AE1/AE3, CK7, CK5/6, CAM5.2) gave negative results.

The histological and immunohistochemical picture of the tumour was consistent with high grade pleomorphic leiomyosarcoma.

Three courses of chemotherapy with Adriamycin were given. Due to evidence of progression observed on X-ray and CT scan and rapid worsening of general status, chemotherapy was discontinued in October 2008.

The patient received symptomatic treatment prescribed by a general practitioner and later was lost from the follow-up.

\section{Discussion}

The criteria describing post-irradiation nature of second malignancy include second malignancy arising within the irradiation field, tumour histology other than primary, and a latent period of 5 years minimum [3]. The present case fits the above criteria, so finally a diagnosis of irradiation-induced sarcoma was made.

The risk of second malignancy within the irradiated area in patients with cervical carcinoma treated with irradiation has been assessed in large epidemiological studies presented by Boice et al. [4] and Kleinerman et al. [5]. Both authors noted increased incidence of rectal, bladder, vaginal and ovarian carcinoma, soft tissue sarcoma and leukaemia. Consistently increasing risk particularly concerns organs receiving a dose higher than $1 \mathrm{~Gy}$, rising from $10 \%$ in the first decade after irradiation to about $50 \%$ after 30 or more years. The risk is highest when irradiation therapy was given at a young age [6-10]. The threshold dose for radiation-induced tumours is not known. A lot of authors have noted increased incidence of soft tissue and bone sarcoma [11-16]. Kleinerman et al. [5] found that relative risk for bone sarcoma in the irradiated field was 3.0. The overall incidence of post-irradiation sarcoma ranged from $0.03 \%$ after 10 years to $0.8 \%$ after 30 years [15, 17-19].

The most common types of radiation-induced sarcomas are osteosarcoma, fibrosarcoma, malignant fibrous histiocytoma, and angiosarcoma [9, 20-22]. High grade pleomorphic leiomyosarcoma has been reported rarely [21, 23]. Lagrange et al. [21] in a retrospective analysis of 80 cases of post-irradiation sarcoma noted 3 cases with soft tissue leiomyosarcoma and one with bone leiomyosarcoma. Kaczmarek-Borowska et al. [23] noted one case with abdominal wall leiomyosarcoma that developed 11 years after cervical carcinoma irradiation. Olcina et al. [24] described one case of radiation-induced leiomyosarcoma after breast carcinoma treatment. Brockstein et al. [25] noted 3 cases of leiomyosarcoma occurring 9-27 years after radiation and chemotherapy. Brockstein et al. [25] were able to find in the English language literature 33 cases (mostly as single case reports) of radiation-induced leiomyosarcoma, which developed 6-35 years after radiation therapy.

Radical resection remains the main method of treatment in radiation-induced sarcomas, but resectability depends on site (bone or soft tissue) and size of tumour. Operability rate ranged from $49 \%$ to $74 \%[16,20,26]$. Management of these

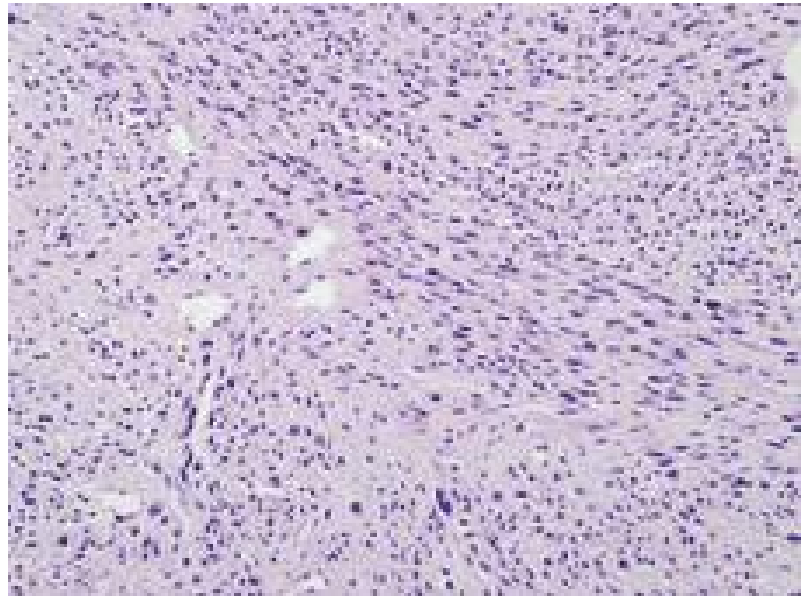

Fig. 1. Malignant spindle cell neoplasm forming either long and storiform fascicles or haemangiopericytoma-like texture

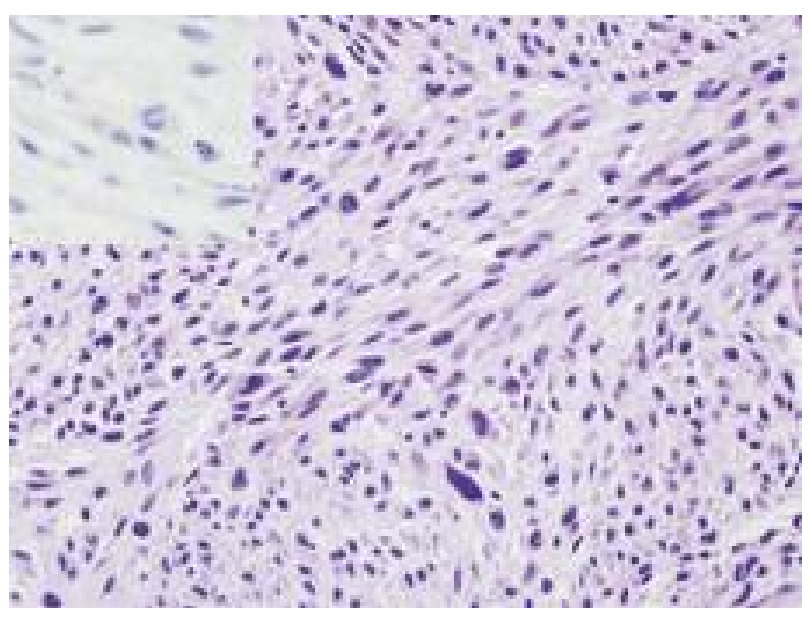

Fig. 2. The tumour cells are characterized by numerous pleomorphic cells and significant mitotic activity (up to 2-3 mitotic figures in one HPF) (Fig. 2). The tumour cells dyed positively with antibodies against vimentin (strong diffuse cytoplasmic reaction), CD68 and desmin (positive reaction in single cells) (Fig. 2. Insert)

tumours must take into consideration the possibility of complete resection and the impact of surgery on quality of life. In the present case, an inoperable sarcoma was located in the pelvic bones. The clinical course was aggressive, with rapid progression during chemotherapy.

The median survival reported by Brady et al. [13] was one year, and the 5 -year survival was $17 \%$ for patients with a tumour of more than $5 \mathrm{~cm}$ in diameter and not completely resected. Bjerkehagen et al. [27] noted 33\% 5-year crude survival. Inoue [18] noted 5-year overall survival for patients with resectable lesion of the extremities at the level of $68.2 \% \mathrm{com}$ pared with $27.3 \%$ for those with central type (pelvis, head/neck, spine, scapula). Similar results were also achieved in other reports $[28,29]$. The poor survival rate is the result of significant delay in diagnosis, large, unresectable and aggressive tumours, and lack of effective methods of treatment apart from radical surgery.

Chemotherapy and re-irradiation have very limited application, mainly as palliative treatment $[26,29]$. Paclitaxel and anti-angiogenic drugs, such as sorafenib and sunitinib, 
have shown some efficiency in angiosarcomas [30] Chemotherapy can be administered in the neoadjuvant pattern, before surgical resection, to improve local control and eradicate subclinical metastatic disease. Guetz et al. [31] noted clinical partial remission in 9 out of 19 patients (47\%) receiving neoadjuvant chemotherapy (doxorubicin + ifosfamide + dacarbazine). Eight of them were operated on. Pathological analysis showed two cases of complete histological response. Re-irradiation can be relatively safe and effective in selected patients, but there are concerns about serious sequelae. Furthermore, repeated high-dose radiotherapy is often impossible due to limited bone marrow function [32, 33]. De Jong [34] indicated re-irradiation plus hyperthermia as a feasible method in patients with post-irradiation sarcoma.

There are several theories describing mechanisms of development of irradiation-induced tumours. Guerrero et al. [35] suggested that critical cellular molecules are directly ionized, or irradiation indirectly acts through mediators such oxygen free radicals and finally DNA injury results in induction of a somatic mutation and activation of proto-oncogene K-ras. Experimental evidence showed p53 gene alterations or increased p53 messenger ribonucleic acid (mRNA) levels in post-irradiation murine sarcomas. The retinoblastoma gen $(\mathrm{Rb}) \mathrm{mu}$ tations also have been detected [36]. Little [37] described evidence indicating that not only activation of oncogenes, tumour suppressor genes and the loss of cell-cycle checkpoints within irradiated cells are important. Genetic consequences of irradiation may occur in the neighbouring cells by gap junction mediated cell-cell communication and activation of the p53 damage response pathway. In Trott's [38] opinion, second cancers in high dose volumes are caused by the promoting effects of chronic radiation damage: atrophy and persistent inflammation. Holt [39] suggested a two-mutation model of carcinogenesis, which fitted the influence of low dose irradiation: a specific mutation in a stem cell increases its rate of proliferation and pre-malignant cells will develop. A second specific mutation in any one of these will make it malignant. Modern radiation techniques such as intensity-modulated radiotherapy (IMRT) might increase the risk of radiation-induced sarcomas. The move from conventional to three-dimensional conformal radiotherapy was implicated in reduction of the normal tissue volume receiving a high dose and an increase in dose to the tumour and a limited part of normal tissue. This may correlate with a decrease in the number of induced sarcomas. However, the move to IMRT involves more fields, and a larger volume of normal tissue receives lower doses while the total body exposure is increased. Both factors may cause greater risk of radiationinduced tumours [19, 38, 40, 41]. Genetic predisposition and other risk factors such tobacco, alcohol, hormonal disturbance and diet also play an important role. The increased risk of second cancers is well documented in patients with hereditary form of retinoblastoma [42]. In members of families with Li-Fraumeni syndrome, germline mutations in tumour suppressor genes may increase the risk of second cancer [43].

The risk of radiation-induced sarcoma is relatively small compared with the benefits of radical or adjuvant radiotherapy. Careful follow-up after effective radiotherapy should be continued for many years: early diagnosis of second cancer may help in more effective treatment of these tumours.

\section{References}

1. International Agency for Research on Cancer. Ionizing radiation, part 1: X-and $\gamma$-radiation and neutrons. IARC monographs on the evaluation of carcinogenic risks to humans. Vol. 75. IARC, Lyon 2000; 138-223.

2. UNSCEAR. Report to the General Assembly with scientific annexes: Sources and effects of ionizing radiation. UNSCEAR, New York 2000; 400.

3. Cahan WG, Woodward HQ, Higinbotham NL, Stewart FW, Coley BL. Sarcoma arising in irradiated bone. Cancer 1948; 1: 3-29.

4. Boice JD Jr, Engholm G, Kleinerman RA, et al. Radiation dose and second cancer risk in patients treated for cancer of the cervix. Radiat Res 1988; 116: 3-55.

5. Kleinerman RA, Boice JD Jr, Storm HH, et al. Second primary cancer after treatment for cervical cancer. An international cancer registries study. Cancer 1995; 76: 442-52.

6. Boice JD, Land CD, Preston DL. Ionizing radiation. In: Cancer Epidemiology and Prevention. Schottenfield D, Fraumeni JF Jr (eds.). Oxford University Press, New York 1996; 319-54.

7. Bhatia S, Robison LL, Oberlin O, Greenberg M, Bunin G, FossatiBellani F, Meadows AT. Breast cancer and other second neoplasms after childhood Hodgkin's disease. N Engl J Med 1996; 334: 745-51.

8. Neglia JP, Friedman DL, Yasui Y, et al. Second malignant neoplasms in five-year survivors of childhood cancer: childhood cancer survivor study. J Natl Cancer Inst 2001; 93: 618-29.

9. Neglia JP, Meadows AT, Robison LL, Kim TH, Newton WA, Ruymann FB, Sather HN, Hammond GD. Second neoplasms after acute lymphoblastic leukemia in childhood. N Engl J Med 1991; 325: 1330-6.

10. Ruka W, Sikorowa L, Iwanowska J, Romeyko M. Induced soft tissue sarcomas following radiation treatment for uterine carcinomas. Eur J Surg Oncol 1991; 17: 585-93.

11. Arai T, Nakano T, Fukuhisa K, et al. Second cancer after radiation therapy for cancer of the uterine cervix. Cancer 1991; 67: 398-405.

12. Boice JD Jr, Day NE, Andersen A, et al. Second cancers following radiation treatment for cervical cancer. An international collaboration among cancer registries. J Natl Cancer Inst 1985; 74: 955-75.

13. Brady MS, Gaynor JJ, Brennan MF. Radiation-associated sarcoma of bone and soft tissue. Arch Surg 1992; 127: 1379-85.

14. Cześnin K, Wronkowski Z. Second malignancies in the irradiated area in patients treated for uterine cervix cancer. Gynecol Oncol 1978; 6 : 309-15.

15. Feigen M. Should cancer survivors fear radiation-induced sarcomas? Sarcoma 1997; 1: 5-15.

16. Mark RJ, Poen J, Tran LM, Fu YS, Heaps J, Parker RG. Postirradiation sarcoma of the gynecologic tract: a report of 13 cases and a discussion of the risk of radiation-induced gynecologic malignancies. Am J Clin Oncol 1996; 19: 59-64.

17. Amendola BE, Amendola MA, McClatchey KD, Miller CH Jr. Radiationassociated sarcoma: a review of 23 patients with postirradiation sarcoma over a 50-year period. Am J Clin Oncol 1989; 12: 411-5.

18. Inoue YZ, Frassica FJ, Sim FH, Unni KK, Petersen IA, McLeod RA. Clinicopathologic features and treatment of post irradiation sarcoma of bone and soft tissue. J Surg Oncol 2000; 75: 42-50.

19. Hall EJ. Intensity-modulated radiation therapy, protons, and the risk of second cancers. Int J Radiat Oncol Biol Phys 2006; 65: 1-7.

20. Pinkston JA, Sekine I. Postirradiation sarcoma (malignant fibrous histiocytoma) following cervix cancer. Cancer 1982; 49: 434-8.

21. Lagrange JL, Ramaioli A, Chateau MC, et al. Sarcoma after radiation therapy: retrospective multiinstitutional study of 80 histologically confirmed cases. Radiation Therapist and Pathologist Groups of the Fédération Nationale des Centres de Lutte Contre le Cancer. Radiology 2000; 216: 197-205.

22. Mavrogenis AF, Pala E, Guerra G, Ruggieri P. Post-radiation sarcomas. Clinical outcome of 52 patients. J Surg Oncol 2011, doi: 10.1002/ jso.22122.

23. Kaczmarek-Borowska B, Koborowicz E, Furmanik F, Sieracki A, Zdunek M. Sawicki M. Mięsak tkanek miękkich jako nowotwór popromienny powstały $w$ wyniku radioterapii raka szyjki macicy. Wiadomości Lekarskie 2004; 7-8: 388-91.

24. Olcina M, Merck B, Giménez-Climent MJ, Almenar S, Sancho-Merle MF, Llopis F, Vázquez-Albadalejo C. Radiation-Induced Leiomyosarcoma after Breast Cancer Treatment and TRAM Flap Reconstruction. Hindawi Publishing Corporation. Sarcoma 2008; Article ID 456950 , doi:10.1155/2008/456950. 
25. Brockstein B, Mundt A, Haraf DJ, Ferguson M, Montag A. Radiationinduced leiomyosarcoma: does antimetabolite chemotherapy contribute? A report of three cases. Sarcoma 2003; 7: 167-72.

26. Sheppard DG, Libshitz HI. Post-radiation sarcomas: a review of the clinical and imaging features in 63 cases. Clin Radiol 2001; 56: 22-9.

27. Bjerkehagen B, Smeland S, Walberg L, et al. Radiation-induced sarcoma: 25-year experience from the Norwegian Radium Hospital. Acta Oncol 2008; 47: 1475-82.

28. Cha C, Antonescu CR, Quan ML, Maru S, Brennan MF. Long-term results with resection of radiation-induced soft tissue sarcomas. Ann Surg 2004; 239: 903-10.

29. Thijssens KM, van Ginkel RJ, Suurmeijer AJ, Pras E, van der Graaf WT, Hollander M, Hoekstra HJ. Radiation-induced sarcoma: a challenge for the surgeon. Ann Surg Oncol 2005; 12: 237-45.

30. Penel N, Marréaud S, Robin YM, Hohenberger P. Angiosarcoma: state of the art and perspectives. Crit Rev Oncol Hematol 2011; 80: 257-63.

31. Des Guetz G, Chaplier A, Mosseri V, Dorval T, Asselain B, Pouillart P. Postirradiation sarcoma: clinicopathologic features and role of chemotherapy in the treatment strategy. Hindavi Publishing Corporation. Sarcoma 2009; Article ID 764379: 1-5.

32. Kasperts N, Slotman BJ, Leemans CR, de Bree R, Doornaert P, Langendijk JA. Results of postoperative reirradiation for recurrent or second primary head and neck carcinoma. Cancer 2006; 106: 1536-47.

33. Riad S, Biau D, Holt GE, et al. The clinical and functional outcome for patients with radiation-induced soft tissue sarcoma. Cancer 2011; doi: $10.1002 /$ cncr.26543.

34. de Jong MA, Oldenborg S, Oei SB, Griesdoorn V, Kolff MW, Koning CC, van Tienhoven G. Reirradiation and hyperthermia for radiation-associated sarcoma. Cancer 2011; doi: 10.1002/cncr.26252.

35. Guerrero I, Villasante A, Corces V, Pellicer A. Activation of a c-K-ras oncogene by somatic mutation in a mouse lymphoma induced by gamma radiation. Science 1984; 225: 1159-62.

36. Strauss PG, Schmidt J, Pedersen L, Erfle V. Amplification of endogenous proviral MuLV sequences in radiation-induced osteosarcomas. Int J Cancer 1988; 41: 616-21.

37. Little JB. Radiation carcinogenesis. Carcinogenesis 2000; 21: 397-404.

38. Trott KR, Gershkevitsh E. Second cancers and leukaemia after curative radiotherapy of cancer. Progress in Radio-Oncology VII. Kogelnik HD, Lukas P, Sedomayer F (eds.). Proceedings of the 7th International Meeting on Progress in Radiooncology ICRO/OGRO 7, Salzburg, Austria, May 15-19, 2002: 733-42.

39. Holt PD. Consideration of tissue response in the application of the two-mutation model to radiation carcinogenesis. Int J Radiat Biol 1997; 71: 203-13.

40. De Smet S, Vandermeeren L, Christiaens MR, Samson I, Stas M, Van Limbergen E, De Wever I. Radiation-induced sarcoma: analysis of 46 cases. Acta Chir Belg 2008; 108: 574-9.

41. Kry SF, Salehpour M, Followill DS, Stovall M, Kuban DA, White RA, Rosen II. The calculated risk of fatal secondary malignancies from intensity-modulated radiation therapy. Int I Radiat Oncol Biol Phys 2005; 62: 1195-203.

42. Fletcher O, Easton D, Anderson K, Gilham C, Jay M, Peto J. Lifetime risks of common cancers among retinoblastoma survivors. J Natl Cancer Inst 2004; 96: 357-63.

43. Hisada M, Garber JE, Fung CY, Fraumeni JF Jr, Li FP. Multiple primary cancers in families with Li-Fraumeni syndrome. J Natl Cancer Inst 1998; 90: 606-11.

\section{Address for correspondence:}

\section{Małgorzata Klimek}

Klinika Ginekologii Onkologicznej

Centrum Onkologii - Instytut im. Marii Skłodowskiej-Curie

ul. Garncarska 11

31-115 Kraków

e-mail: klimekmag@poczta.onet.pl

Submitted: $\quad$ 15.01.2011

Accepted: $\quad$ 18.01.2012 